\title{
LAS RELACIONES DIPLOMÁTICAS \\ ENTRE LA ESPAÑA LIBERAL Y LA GRECIA INSURRECTA: LA MISIÓN DE ANDREAS LOURIOTIS EN MADRID (1822)*.
}

\author{
Eva LATORRE BRoto
}

España

Resumen: En el presente trabajo ofrecemos el relato histórico, hasta ahora muy fragmentario, de las relaciones políticas entre la España liberal y la Grecia revolucionaria durante los primeros años de la revolución (1821-1823), gracias al descubrimiento de unos documentos inéditos que pertenecieron a Andreas Luriotis, enviado a Madrid por el gobierno provisional de Corinto en 1822.

Palabras clave: Filohelenismo Español - Guerra de Independencia Griega - Revoluciones Liberales - Relaciones España-Grecia - Siglo XIX - Andreas Luriotis

\section{DIPLOMATIC RELATIONS \\ BETWEEN SPAIN AND THE INSURGENT LIBERAL GREECE: ANDREAS LOURIOTIS' MISSION IN MADRID (1822)}

Abstract: This paper offers the first cohesive historical account of the political relationships between liberal Spain and revolutionary Greece during the earliest period of the Greek Struggle for Independence (1821-23). It overcomes previous, rather fragmentary attempts, by relying on a set of newly discovered, unpublished documents once belonging to Andreas Louriotis, commissioner of the Provisional Government in Corinth sent to Madrid in 1822.

Key-words: Spanish Philhellenism - Greek War for Independence - Liberal Revolutions - Relationships Spain-Greece - 19th Century Andreas Louriotis

Recibido: 17.12.2014 - Aceptado: 16.01.2015

\footnotetext{
* Ver esta nota al final del artículo.
} 
Eva LAtorre Broto: Las relaciones diplomáticas entre la España liberal y la Grecia...

\section{Correspondencia: Eva Latorre Broto.} evalatorrebroto@gmail.com

Licenciada en Filología Griega (c) Doctora Universidad Complutense de Madrid Asociación Cultural Hispano-Helénica.

General Ricardos 230, 5 B. 28025 Madrid. España.

$\mathrm{C}^{\mathrm{n}}$ el volumen 32 de la revista Erytheia correspondiente al año C2011 trazamos un panorama general del filohelenismo en España centrándonos en sus aspectos histórico y político y dejando a un lado el literario, merecedor de estudio en sí mismo. El citado trabajo estaba articulado en tres partes: 1) Relaciones políticas entre la España Constitucional del Trienio Liberal y el Gobierno Provisional de Grecia; 2) Recapitulación de los datos conservados sobre los españoles cuya presencia está documentada en la Grecia revolucionaria para fijar la nómina y establecer métodos sistemáticos de trabajo que ayuden a su identificación; y 3) Propuesta de inclusión del Capitán Barona en esa nómina a través del estudio de su biografía, opúsculo a caballo entre la literatura y la historia ${ }^{1}$.

Como ya mencionamos en su momento, el trabajo fundacional sobre el filohelenismo español fue obra del historiador Zanos Vaguenás, quien entresacó de los monumentales Archivos del Renacimiento Griego hasta el establecimiento del Reino ${ }^{2}$ y de los Archivos Generales del Estado ${ }^{3}$ los documentos relativos a los primeros contactos políticos entre España y Grecia y a los militares españoles que prestaron sus servicios allít. Décadas después, los profesores Yanis Jasiotis y Victoria Jadsigueorguíu-Jasioti revisarían

${ }^{1}$ Cf. Latorre (2011).

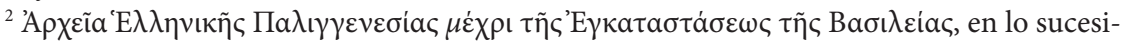
vo AEP. Los volúmenes están digitalizados en http://paligenesia.parliament.gr/.

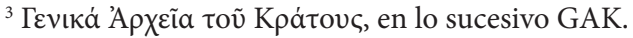

${ }^{4}$ VAGUenás (1955). El propio Vaguenás refiere que este primer volumen de la revista $\Phi \iota \lambda \varepsilon \lambda \lambda \eta v \iota \kappa \alpha ́$, dedicado al filohelenismo en la Península Ibérica, fue realizado con motivo de la primera visita oficial a España y Portugal del presidente Papagos, del vicepresidente y ministro de Asuntos Exteriores Stefanópulos y del ministro de la Presidencia del Gobierno Rallis, realizada en octubre de 1954. Cf. ibidem, p. 94. 
el tema añadiendo datos dispersos en estudios varios bien sobre filohelenismo, bien sobre el liberalismo español, como la obra del profesor Alberto Gil Novales. A pesar de este enriquecimiento, la documentación presentaba grandes vacíos que exigían una revisión crítica de la acumulación de datos y, en ocasiones, hipótesis más o menos arriesgadas para vincularlos.

El presente trabajo está concebido como una suerte de addenda et corrigenda a la primera parte de nuestro estado de la cuestión, esto es, la que analizaba las relaciones tempranas entre España y Grecia, pues documentos que hasta ahora no habían sido utilizados para el estudio de este tema en concreto añaden piezas fundamentales al rompecabezas. Si bien quedan aún algunas lagunas, podemos trazar una narración más o menos continuada de los acontecimientos gracias a la misión desempeñada por Andreas Luriotis, enviado del Gobierno Provisional griego, en el Madrid de finales de $1822^{5}$.

\section{El Comité Filohelénico de Madrid.}

Las noticias que llegaban de Oriente sobre la insurrección contra el Sultán en los Principados del Danubio y luego en la Morea fueron acogidas con alborozo en una España que apenas hacía un año que volvía a paladear el sabor de la libertad. Por citar un ejemplo, el periódico El Censor afirma:

«Si alguna vez hubo en el mundo una insurrección y una causa que puedan llamarse santas, son ciertamente las de los griegos. [...] Se levantan, se arman para conquistar los bienes más preciosos, y para salir del mísero estado en que los tienen sus feroces opresores. Esclavos con el nombre de vasallos, y viviendo bajo el gobierno más despótico y arbitrario que se conoce, sujetos a los caprichos omnipotentes de los bajaes que los gobiernan, sin garantía ninguna para sus personas y

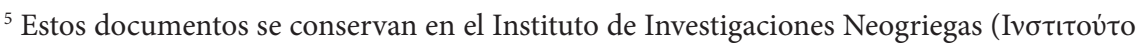

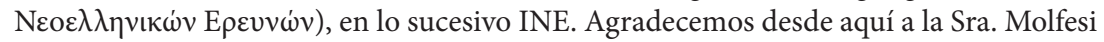
la atención que nos dispensó durante nuestra investigación en el INE.
} 
propiedades, dominados por unos bárbaros enemigos de toda ilustración, pobres, habitando los más fértiles territorios, y obligados a contribuir para mantener el lujo de un voluptuoso serrallo sin que el indolente diván cuide de fomentar ninguno de los ramos de la pública prosperidad: ¿hubo jamás un pueblo que con más justicia se haya armado para resistir a la opresión?» ${ }^{6}$

Si la publicación más conservadora del Trienio que, al inicio de ese mismo artículo, deseaba sin embargo que se apagara «el fuego ya encendido», dedicó tales palabras a la revolución griega, consideramos innecesario abundar en el entusiasmo manifestado por otras cabeceras de tendencia liberal y exaltada.

De hecho, según cuenta el conde italiano Alerino Palma di Cesnola, el que está considerado como uno de los primeros comités filohelenos oficiales fue fundado en Madrid por el inglés John Bowring, quien

«May and should be looked upon as the principal author of the loan obtained for Greece [in London], having paid attention to that object, when I recommended to him, by letter in September 1822 from Madrid, Mr. Luriottis, who had been the bearer of other letters from the Greek Government to the Philhellenic Committee, established at the end of 1821, or at the commencement of 1822, at Madrid, by Mr. Bowring himself. I was member and secretary of that Committee. Mr. Luriottis, having lost all hope of obtaining pecuniary aid from the Spanish Committee, went, as I had advised him, from Madrid to London.

\footnotetext{
${ }^{6}$ «Insurrección de la Grecia», El Censor n 48, 30/06/1821, pp. 459-460. Según informaciones de www.bne.es: «Es dirigida por el afrancesado sacerdote Sebastián Miñano, al que se suman en la redacción los también clérigos josefinos y literatos Alberto Lista y José Manuel (sic) Gómez Hermosilla, empezando a publicarse el 5 de agosto de 1820. De carácter constitucionalista, su tendencia es de un liberalismo supermoderado, enmarcado en el despotismo ilustrado». Simón (1986): 361-362, añade que la publicación estaba financiada desde Francia, y que llegó a convertirse en la peor enemiga del Gobierno constitucional hasta que éste decretó su cierre en julio de 1822, después de la fallida insurrección absolutista del Siete de Julio.
} 
The Minister for Foreign Affairs, San Miguel, had treated him with the same courtesy as he had treated the Holy Alliance»?

Estas fechas encajan a la perfección con el primer testimonio conservado de las relaciones entre España y la Grecia moderna, con cuyo análisis Vaguenás iniciaba su estudio ${ }^{8}$.

El 18 de diciembre de 1821, tres supuestos diputados españoles se dirigían al Gobierno Provisional griego para transmitirle los deseos de 300 soldados italianos exiliados que se encontraban en España y que deseaban entregar sus vidas a la causa griega a cambio de la ciudadanía, expresando su admiración por esa lucha a la que todos los españoles acudirían sin dudar si la libertad propia estuviera segura. Por último, ofrecían relaciones oficiales y ayuda, con el pie

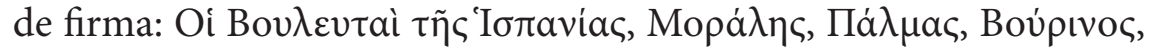
esto es, «Los diputados de España Moralis, Palmas y Búrinos».

Este documento, cuyo original francés no hemos logrado hallar todavía, se conserva en dos versiones griegas sin variaciones importantes salvo la alternancia Boúpıvoc/Bópıvc, esto es, «Búrinos/ Borins» en el nombre del tercer diputado. Jassiotis había propuesto la identificación del apellido «Moralis», adaptado a la declinación griega, con Francisco Díaz de Morales y Bernuy, diputado por Córdoba en el Parlamento español entre julio de 1820 y febrero de 1822, pero los otros dos firmantes permanecían aún sin determinar9. El hecho de que en las listas de Diputados en Cortes 'Morales' fuera el único nombre susceptible de coincidencia nos indujo a plantear sendas hipótesis para el esclarecimiento de los otros dos nombres ${ }^{10}$.

En primer lugar, dado que Díaz de Morales fue un comunero convencido de quien se dice que introdujo el carbonarismo en España ${ }^{11}$,

${ }^{7}$ Conde de Palma, Greece vindicated, p. 7. Sobre el Comité Filohelénico madrileño, vd. ST. Clair (2008): 142.

${ }^{8}$ AEP, A', p. 235, apud Vaguenás (1955): 6-8. Vd. Doc. 1 en Latorre (2012): 227-229, donde se ofrece también traducción española del original griego.

${ }^{9}$ Jassiotis (2008): 121.

${ }^{10}$ Cf. Latorre (2011): 282-285.

${ }^{11}$ Gil Novales (1975: 737 y 811). 
era fácil relacionarlo con el líder de los carbonarios insurgentes del Piamonte en marzo de 1821, el conde Alerino Palma di Cesnola, a quien propusimos como segundo firmante. El ya citado testimonio del Conde hablando de su presencia en Madrid en la fecha de esta carta confirma nuestra suposición, pues después del fracaso de la revolución liberal en el Piamonte se refugió en España junto a sus tropas, que le considerarían su «Príncipe Capitán General», y que serían estos “300” que ofrecían sus vidas a cambio de la ciudadanía griega.

En segundo lugar, propusimos que el nombre que quedaba por identificar podría ser el resultado de la lectura errónea de "Bernuy", el segundo apellido de Díaz de Morales, que en una rúbrica manuscrita de caligrafía poco clara quedó registrado con las variantes Búrinos/ Borins por los traductores. Por otra parte, teniendo en cuenta la extrañeza que en los griegos genera la exuberancia de los apellidos compuestos españoles, suponíamos que los traductores simplificaron los nombres, pues también nos llamaba la atención la ausencia del apellido "Díaz" en el pie de firma. Así pues, los tres firmantes de la versión griega y oficial, Moralis, Palmas y Búrinos/Borins, bien podían reducirse a dos, Díaz de Morales y Bernuy y el Conde de Palma.

$\mathrm{Si}$ bien acertamos en nuestra primera hipótesis proponiendo como uno de los firmantes al Conde de Palma, quien con el tiempo se convertiría en uno de los más ilustres filohelenos ${ }^{12}$, en la segunda acertamos sólo a medias. Cierto es que los traductores griegos simplificaron el primer apellido de Díaz de Morales consignándolo como «Moralis» pero, según confirma el documento que veremos a continuación, las variantes Búrinos/Borins no transcribían "Bernuy", sino "Bowring", el apellido del fundador del Comité Filohelénico de Madrid. John (más tarde Sir John) Bowring, fue un comerciante británico de vasta formación cultural cuyos negocios le permitieron establecer contacto con los círculos progresistas de toda Europa. Fueron precisamente estas actividades de Bowring lo que despertó en la Santa Alianza la sospecha de que las revoluciones de España,

${ }^{12}$ Barth-Kehrig-Korn (1960): 197. Cf. LAtorre (2011): 284, n. 11. 
Italia y Grecia respondían a una conspiración internacional, aunque algunos lo tenían por un simple espía británico ${ }^{13}$.

Así pues, los iniciales «tres diputados españoles» del documento han quedado reducidos a uno, Díaz de Morales, cuyo cargo los intérpretes griegos hicieron extensivo a los otros dos nombres en una traducción no demasiado cuidada, todo hay que decirlo. En cualquier caso, el trío de firmantes asocia el interés efectivo y el compromiso con la Grecia en armas a los sectores más exaltados del espectro político liberal español e internacional, y aunque la lógica dicta que el Comité Filohelénico Español debió fundarse en el seno de alguna sociedad patriótica, aún carecemos de pistas sobre en cuál de ellas pudo ser.

\section{El primer filoheleno español: Francisco Díaz de Morales y Bernuy.}

Aunque en su breve referencia Palma no menciona a Díaz de Morales entre los fundadores de ese Comité, la coincidencia de fechas y nombres hace suponer que la primera actividad llevada a cabo después de su fundación fue su toma de contacto con el Gobierno Provisional griego y su ofrecimiento de ayuda, lo que incluiría a Díaz de Morales entre sus miembros activos y, gracias a su acta de Diputado en Cortes, también entre los de mayor rango ${ }^{14}$.

Al no encontrar documentada ninguna respuesta del Parlamento griego, Vaguenás consideró probable que no la hubiera, suponiendo que en esos primeros meses el Gobierno griego deseaba demostrar

${ }^{13}$ ST. Clair (2008): 141. A finales de 1821 Bowring se encontraba en España reclamando al Gobierno un empréstito realizado cuando él era contratista del ejército de Wellington en 1813.

${ }^{14}$ Francisco Díaz de Morales provenía de una familia aristocrática de Córdoba y llegó a ser capitán de Artillería en el Ejército. Tomó parte en la conjura del general Lacy, lo que le valió una condena a muerte de la que le libró in extremis la noticia del triunfo de Riego cuando estaba camino del cadalso el 18 de marzo de 1820. A partir de entonces renunció al Fuero Militar y se integró en la Milicia Nacional, estando siempre muy comprometido con distintas sociedades patrióticas. También ejerció como periodista. Siempre fue un libertario convencido e íntegro que denunció los abusos y las hipocresías de los liberales moderados, y que murió en la indigencia más absoluta. Vd. GIL Novales (1975): 810-811. 
a la Santa Alianza que su insurrección no respondía a una ideología revolucionaria, sino al deseo y a la necesidad de construcción nacional. Acoger en su seno a los carbonarios piamonteses fugitivos habría implicado significarse en exceso.

No obstante, Vaguenás transcribe una notificación en la que, con fecha 5 de abril de 1822, el Parlamento griego comunica al Ejecutivo que considera "provechosa la relación con España», de lo que deduce que la cuestión se trató diplomáticamente en sesión parlamentaria y ya no fue más allá ${ }^{15}$.

Pero lo cierto es que, tal y como suponíamos en nuestro anterior trabajo, sí hubo respuesta por parte del Gobierno griego a este ofrecimiento que venía de España, y además fue inmediata y llena de esperanza. Tan sólo cinco días después, el Secretario de Estado y Ministro de Asuntos Exteriores Teodoro Negri se dirigía en francés a «Monsieur Dias (sic) de Morales, Député aux Cortes d'Espagne à Madrid» con un despacho que va identificado con el «No $65 \mathrm{du}$ Protocole» del Ministerio de Asuntos Exteriores ${ }^{16}$.

Negri acusa recibo «de sus cartas dirigidas al Senado y al Príncipe Ipsilandi con fecha 18 de enero de $1822 »^{17}$ y acepta con gratitud y orgullo a esos patriotas italianos que tanto han hecho ya por la libertad, garantizando sus grados militares y prometiendo recompensas según sus méritos. Pide además que traigan con ellos a cuantos soldados armados les sea posible reunir, pues da por sentado el apoyo de los españoles aunque sabe las dificultades que atraviesan. Será España, "pueblo generoso», quien dé a Europa el ejemplo que

${ }^{15} \mathrm{Vd}$. Doc. 2 en Latorre (2012): 230. Vaguenás (1955): 9. Jatsigueorguiou-Jassiotis (2000): 147, y Jassiotis (2008): 121, aceptan esta hipótesis.

${ }^{16}$ Cf. LAtorre (2011): 285-287. Vd. Doc. 3 en Latorre (2012): 231-232. La carta está fechada en "Corynthe le 10/22 avril 1822», según la costumbre griega de señalar en los documentos de ámbito internacional la fecha del calendario juliano junto a la del gregoriano. Dado que el Doc. 2 es una comunicación interna del Parlamento, sólo presenta la fecha local, el 5 de abril.

${ }^{17}$ La carta del Comité Filohelénico está fechada el 18 de diciembre de 1821. La única explicación que encontramos a esta variación es que sea la fecha de esa otra carta dirigida a Ipsilandis, bien por Díaz de MoÅrales o bien por el Comité, que aún no hemos podido localizar. 


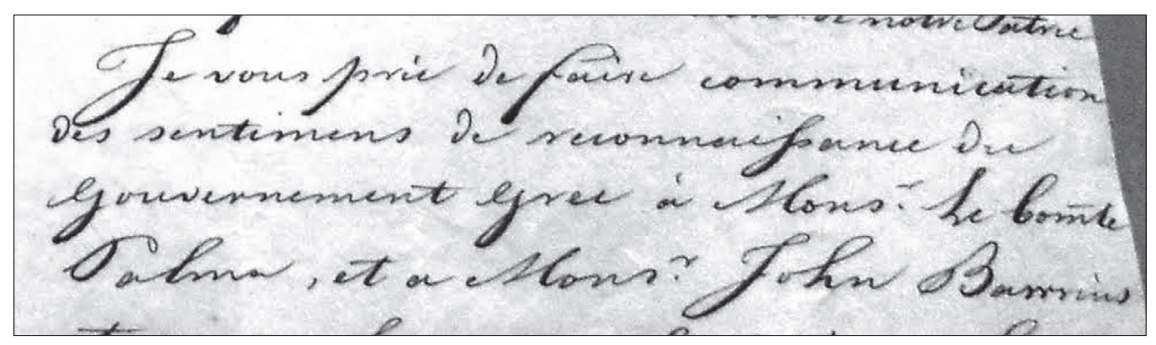

permitirá a Grecia consolidar su libertad, y Negri se toma la confianza de designar a Díaz de Morales como su valedor en España, Portugal y América, para lograr ayuda $y$, lo que resulta vital, el reconocimiento legal de su Gobierno por parte de los respectivos Gabinetes, pues «Grecia no podrá gozar de sólida consistencia hasta que

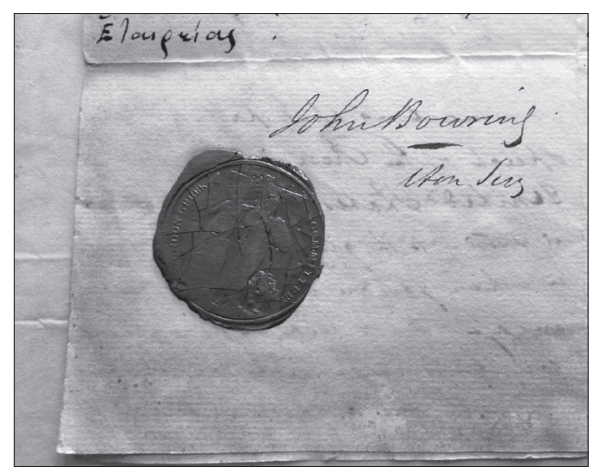
sea reconocida por las potencias». Continúa presentando a Andreas Luriotis, su legado oficial, quien le hará llegar una copia de la «Ley Orgánica» griega y una fiel descripción de la situación del país, y, para finalizar, le ruega transmita su reconocimiento al Conde de Palma y a John Bowrins (sic).

Negri nos confirma así el triunvirato firmante de la carta del Comité Filohelénico de Madrid, lo que permite deducir que la primera vez que llegó a Grecia el nombre de Bowring, cuyo papel en el Comité Griego de Londres resultó crucial para conceder los préstamos que otorgarían a Gran Bretaña el protagonismo en la Revolución griega, fue sobre un documento español ${ }^{18}$.

La desesperación de Grecia por conseguir entablar relaciones de Estado a Estado se trasluce en el entusiasmo con que Negri redacta esta carta y en las grandes expectativas que despierta en él la condición

\footnotetext{
${ }^{18}$ Bowring fue también fundador del Comité Griego de Londres en marzo de 1823. Según se puede comprobar en las fotografías, la firma autógrafa de Bowring puede ser fácilmente transcrita como "Bowrins" por alguien que la lee por primera vez.
} 
de diputado en Cortes de Díaz de Morales presumiéndole tan gran capacidad de influencia política ante el Gobierno español y a nivel internacional. A esas alturas ya habían acudido a Grecia numerosos particulares filohelenos -idealistas, exiliados o buscavidas - para sumarse a la lucha, pero ésta parece ser la primera vez que un cargo político extranjero les presentaba sus respetos. Tanto la situación interna como su relación con las ex-colonias eran calamitosas, pero es lógico que Grecia pensara que las viejas glorias del Imperio y su defensa del sistema constitucional otorgaban a España cierto ascendente como generadora de opinión en América. Los acontecimientos demostrarán que Negri pecaba de excesivo optimismo.

\section{Andreas Louriotis, embajador de Grecia en España.}

Consciente de su precariedad, la Grecia en ciernes se apresura a dotarse de instituciones que la conviertan en Estado y, así, en diciembre de 1821 se reúne la Asamblea Nacional en Epidauro, que el día 1 de enero de 1822 presenta la Constitución y forma el Gobierno Provisional con Dimitrios Ipsilandis como presidente de la Asamblea, cargo prácticamente honorífico. Como presidente del Parlamento, Aléxandros Mavrocordatos gozará de todo el poder ejecutivo, y ocho ministros asumirán las distintas responsabilidades de la nueva nación ${ }^{19}$. La Revolución se consolida, mal que les pese a algunos. En España, en cambio, los avances griegos se anuncian con sincero regocijo:

«Trieste, Venecia y Liorna son también otros tres puntos que tiene el Austria para propagar las noticias de la Grecia que más le acomoden. Pero no puede impedir que se sepan los progresos que el nuevo gobierno heleno va haciendo en todos [los] ramos. Ya se dicen los nombres de sus nuevos agentes diplomáticos, a saber: para Rusia el obispo Ignacio y otros dos; para Francia el Dr. Corai, Juan Zaini (sic) y Demetrio Penica; para Inglaterra a Juan Calania y otro; para Austria a Papadiamandopulo, Juan

${ }^{19}$ BREWER (2001): 129. 
Orlando y Antonio Galli; para los Países Bajos a Drosso Morali y otro; para Nápoles, Roma y Toscana un solo agente; y dos para España, cuyos nombres se ignoran $»^{20}$.

Un cuerpo diplomático era un recurso básico para proyectarse como un Estado moderno en el escenario internacional del que Grecia quería formar parte cuanto antes para lograr financiación, lo que resultaba imposible si no mediaba el reconocimiento oficial como Estado. Teniendo en cuenta que las noticias solían tardar unos dos meses en llegar de Grecia a Europa occidental ${ }^{21}$ y que esta información se publicaba a finales de mayo de 1822 en Madrid, lo más probable es que se gestara en Grecia a principios de abril, coincidiendo con la resolución del Parlamento en la que se aprueban las relaciones con España.

Dos legados venían destinados a España aunque, a la vista de los hechos, el único que llegó fue Andreas Luriotis, ya anunciado por Negri en su carta a Díaz de Morales y hombre de confianza del presidente Mavrocordatos. No hay aún datos concretos sobre el viaje de Luriotis, y el único punto de partida es la ya mencionada carta de recomendación que el Conde de Palma le escribió para John Bowring en Madrid en septiembre de 1822, fecha en que Bowring, por cierto, se encontraba en Francia ${ }^{22}$.

No obstante, aquí falla la secuencia cronológica de los acontecimientos. Gracias a la carta de Negri, cuya existencia presuponíamos en nuestro anterior trabajo, ya cobra pleno sentido la expedición a Grecia para la que el capitán napolitano Giuseppe Rossaroll, carbonario residente en Barcelona, convoca, «al efecto de socorrer a sus hermanos los griegos y consagrar su vida en esta santa causa [...] a todos los italianos e individuos pertenecientes a cualquiera nación, que sienten en sus corazones el sagrado fuego de la libertad», y que publicó en El Tribuno el 30 de junio de 1822 a

\footnotetext{
${ }^{20}$ El Universal, 31/05/1822, p. 1.

${ }^{21}$ ST. Clair (2008): 51.

${ }^{22}$ Cf. infra n. 31.
} 
través de Constantino Viceré, su agente en Madrid ${ }^{23}$. Pero si Luriotis era en teoría el portador de esa carta, y llegó a España en septiembre ¿cómo pudo Rossaroll saber en junio de esa aceptación? ${ }^{24}$.

La única explicación posible por el momento es que, ante la necesidad perentoria de hombres y armas, Negri enviara, por cualquier otro medio, una comunicación oficiosa solicitando la incorporación inmediata de los “300”25. En realidad, en ningún momento se dice que Andreas Luriotis sea el portador de la misma; tan sólo que será él el encargado de remitir la documentación ofrecida y de abrir los cauces de comunicación oficial. Dada la trascendencia de las cuestiones a convenir, quizá Negri se tomara más tiempo para pensar la estrategia que atraería definitivamente a España a la causa griega y preparar también la embajada Luriotis, al que le daría una copia de esta carta para acreditar su identidad. No obstante, desde que el Comité Filohelénico escribiera a Grecia honrándose de su amistad y ofreciéndole ayuda en nombre de España hasta que Luriotis llegó para hacerla efectiva había pasado casi un año, y todo había cambiado.

\section{Madrid, otoño 1822.}

Los sucesos del Siete de Julio, en los que la Milicia Nacional logró aplastar la insurrección de la Guardia Real de Fernando VII, instigada por él mismo, dinamitaron el ya de por sí frágil consenso — si lo hubo

${ }^{23}$ Texto completo en LATORRE (2011): 285-287. Señalado por Gil Novales (1975): 189, n. 24.

${ }^{24}$ Una reflexión más profunda en torno a una noticia sobre Rossaroll que ya mencionamos en LATORRe (2011): 286, provoca nuestra perplejidad. ST. Clair (2008): 252, dice que «In late 1824 a certain General Rossaroll arrived at Zante on his way to Greece from Spain». Las referencias bibliográficas que St. Clair proporciona sobre Rossaroll son un tanto confusas y no nos ha sido posible todavía seguirle la pista a este dato. Dos años y medio de diferencia entre su convocatoria y su llegada a Zante es demasiado tiempo, y más para exiliados que no tenían otro sitio donde ir. ¿Cabe la posibilidad de que, aunque la convocara, no llegara a llevar a cabo la expedición? Aunque hubiera sido así, esto no invalida el hecho de que tuvo que tener conocimiento previo de la aceptación de sus servicios por parte de Grecia para convocarla.

${ }^{25}$ Negri fechó su carta el 10/22 de abril de 1822, y la convocatoria de Rossaroll se anunció el 30 de junio. Este intervalo de unos dos meses es el tiempo que tardaban habitualmente las noticias en llegar de una parte a otra del Mediterráneo. Cf. nota 21 y LATORRE (2011): 286. 
alguna vez-entre las fuerzas políticas. La tibia reacción del gabinete moderado de Francisco Martínez de la Rosa ante este baño de sangre generó tal indignación social que hizo caer al gobierno.

Como reconocimiento al papel desempeñado al frente de la Milicia Nacional que, con el improvisado 'Batallón Sagrado', logró frenar a los grupos serviles que intentaban entrar en Madrid para apoyar a la Guardia Real, el 5 de agosto de 1822 se confía la formación de un nuevo gobierno al coronel exaltado Evaristo Fernández San Miguel, quien había acompañado al general Rafael del Riego en el levantamiento de las Cabezas de San Juan en 1820, y estaba tan cercano a él que incluso se le atribuye la letra de su Himno.

Su nombramiento como Primer Secretario de Estado, cargo equivalente al de Ministro de Asuntos Exteriores, inquietó a las Potencias y no satisfizo a los sectores nacionales más radicales que hubieran querido llegar hasta el fondo del asunto del Siete de Julio. San Miguel pertenecía a la Sociedad del Anillo, que, paulatinamente, había ido moderando su liberalismo. Sus enjuagues y pasteleos como se empezaron a llamar entre los grupos de descontentos las manipulaciones que San Miguel, como fiscal de la causa, fue introduciendo en los juicios- terminaron reduciendo a simple insurrección militar lo que había sido una conspiración política en toda regla, y los verdaderos culpables, con el Rey a la cabeza, quedaron exonerados de responsabilidad ${ }^{26}$. Entre las distintas facciones liberales se abrió un abismo y las posiciones se extremaron ${ }^{27}$.

En el mes de octubre se inaugura el Congreso de Verona, donde Francia, Austria, Prusia y Rusia plantean la intervención armada en España para restaurar el poder absoluto de Fernando VII, quien no

\footnotetext{
${ }^{26}$ Sobre el Siete de Julio $v d$. Gil Novales (1975): 665-681. De San Miguel como fiscal de la causa y anillero encubierto, ibidem, p. 674.

${ }^{27}$ Álvaro Flórez Estrada traza un completo panorama de las facciones políticas del momento: «Los que se oponían a que se menguase la libertad concedida por la Constitución y a toda providencia contraria a lo que ella prevenía, a los cuales indistintamente se les daban los nombres de "exaltados", de "anarquistas", de "tragalistas" y de "zurriaguistas". Los que sin
} 
había dejado de pedirles ayuda en secreto. Al mismo tiempo que el presidente San Miguel respondía con protestas patrióticas a los embajadores de las Potencias en España, el general Mina lanzaba una ofensiva para aplastar las asonadas serviles que surgían por casi todo el territorio nacional como estallidos de combustión espontánea que había que apagar con celeridad, pues corrían grave riesgo de estabilizarse, como ocurrió con la Regencia de Urgel.

En un Madrid en plena efervescencia por la situación política interna y las amenazas externas, Andreas Luriotis no encontró ni a Bowring ni a Díaz de Morales y tuvo que improvisar.

\section{Andreas Luriotis en la Sociedad Patriótica Landaburiana.}

La Sociedad Landaburiana se fundó el 24 de octubre de 1822 en memoria de Mamerto Landáburu, teniente de la Guardia Real asesinado por sus compañeros serviles en julio por no haber querido sumarse a la insurrección. Los más insignes representantes del liberalismo exaltado se dieron cita allí convencidos en un primer momento de que, superado el Siete de Julio, el sistema constitucional se había consolidado ${ }^{28}$. En su tertulia inaugural hablaron los ciudadanos Juan Romero Alpuente, su presidente, Pedro Pascasio Fernández Sardinó, Manuel Gorostiza, Juan Mac-Crohon, Juan Florán, marqués de Tabuérniga, y Félix Mejía y Benigno Morales, redactores de El Zurriago, la publicación más odiada y temida de todo el Trienio Liberal por lo descarnado y exaltado de sus críticas ${ }^{29}$, que desde sus páginas se felicitó por la fundación de esta sociedad

querer un gobierno absoluto, aspiraban, aparentando amar la Constitución para realizar su plan, a que ésta se reformase, dando al Rey más ensanches y estableciendo unas cámaras cuya autoridad dimanaba de éste y no de la Nación, por cuyo medio creían atraer al partido que deseaba el gobierno absoluto, y mejorar y consolidar su rango: se les daban los nombres de "moderados", "anilleros" y "pasteleros". Los que, o fingiendo convenir con éstos o abiertamente, trabajaban porque se restableciese el "régimen absolutista", eran conocidos por el nombre de "absolutistas", y más comúnmente por el de "serviles"», apud Zavala (1971): 45.

${ }^{28}$ Sobre la Sociedad Patriótica Landaburiana, vd. GiL Novales (1975): 681-733.

${ }^{29}$ Sobre El Zurriago se ha escrito mucho. Lo más reciente es su edición comentada de Ángel Romera, El Zurriago (1821-1823). Un periódico revolucionario, Fundación Municipal de Cultura (Biblioteca de las Cortes de Cádiz, 5), Cádiz 2005. 
patriótica. La publicación El Indicador se convirtió en el órgano de comunicación oficial que recogía las actas de las sesiones de la Sociedad, pero también desde El Zurriago podía seguirse el pulso de la misma, aunque desde el punto de vista personal de sus redactores. Así, en el ejemplar coetáneo de la primera sesión de la Sociedad, el cual salió publicado la primera semana de noviembre, Mejía y Morales declaran solemnemente haber formado parte del Batallón Sagrado y haber permanecido con las armas en la mano batiéndose "con los guardias rebeldes con un entusiasmo propio de hombres libres» con el fin de defenderse de la acusación de deserción que $E l$ Espectador, el periódico de Evaristo Fernández San Miguel, había lanzado contra ellos para desacreditar las constantes denuncias $\mathrm{y}$ versos mordaces con los que estaban dispuestos a llegar hasta el fondo de los pasteleos del Siete de Julio ${ }^{30}$. Podríamos decir que, aunque en un clima de optimismo político, ya desde su fundación la Landaburiana no se iba a conformar con las componendas del presidente San Miguel.

La fecha coincide con los días en que Luriotis debió andar por Madrid preguntando por sus contactos, y es seguro que, si el propio Luriotis no estuvo ya el mismo día en que fue fundada, todos los interpelados le indicarían la dirección de la Landaburiana, pues allí había gente que podría darle razón.

Gorostiza, por ejemplo, era íntimo amigo y colaborador de José Joaquín de Mora, redactor de El Indicador. Mora demostró ser fiel amigo de John Bowring cuando escribió una sentida defensa en su honor después de que éste fuera apresado en Calais por la policía francesa en octubre de 1822 con un despacho secreto del embajador portugués en París sobre la invasión de España por tropas militares francesas ${ }^{31}$.

${ }^{30}$ El Zurriago, no 74 , pp. 11-14.

${ }^{31}$ El Indicador, $\mathrm{n}^{\circ} 175,26 / 10 / 1822$, p. 837. Periodista, escritor y traductor, Mora fue uno de los más importantes personajes de la intelectualidad liberal, tanto en España como en sus años de exilio en Inglaterra y después en América Latina. En 1819 viajó a Italia para entrevistarse con Ioanis Capodistrias y, aunque no lo consiguió, allí conoció, entre otros, a John Bowring y Jeremy Bentham, los principales defensores del Estado Constitucional 
Por otra parte, Gorostiza y Mora habían sido redactores de $E l$ Correo General de Madrid (1820-1821) junto a Félix Mejía ${ }^{32}$, quien redactaba El Zurriago con Benigno Morales. En El Zurriago había escrito también el coronel Atanasio Lescura, fundador de La Tercerola. Ambas publicaciones comenzaron una fructífera colaboración, hasta el punto de que Mejía asumió también La Tercerola cuando sus números 9 y 10, y alguno de El Zurriago, le costaron a Lescura el tener que huir de Madrid en marzo de 1822 al estar siendo buscado por la autoridad. No podemos olvidar que Atanasio Lescura se refugió en Cartagena y terminó tomando un barco rumbo a Corinto en abril ${ }^{33}$. Las investigaciones policiales revelaron en agosto de 1824 que en El Zurriago hubo un tercer redactor, el librero José Sáenz Urraca, quien también había participado en La Tercerola ${ }^{\circ} 11$ junto a Díaz de Morales ${ }^{34}$.

Preguntando y buscando a Díaz de Morales, a quien iba encomendado por su gobierno, Luriotis debió ir a parar al núcleo duro del liberalismo comunero formado por los personajes más exaltados y radicales, los únicos que, ante el panorama político nacional e internacional que España atravesaba en aquellos momentos, podían ser receptivos a su mensaje. Y consiguió implicarlos, pues en la reunión de la Landaburiana del 3 de noviembre de 1822:

«El ciudadano Gorostiza sube a la tribuna: Dos cuadros interesantes, dice, ocupan en la actualidad la atención del hombre observador. Uno, con coloridos vivos y animados representa la España; otro, aunque bosquejado solamente, cuando se le examina de cerca, se conoce harto bien la maestría del pincel que ha dado la idea; éste es la Grecia. Y por qué, pues, continúa el orador, nuestro ministerio de Estado no ha pensado todavía en que la libre España se una con vínculos estrechos de amistad con los descendientes de los Arístides y Epaminondas?

español y después de la causa griega en Inglaterra, $v d$. GiL Novales (1975): 887-888, y LLORÉNS (2006): 44-45.

${ }^{32}$ LLORÉNS (2006): 46.

${ }^{33}$ Latorre (2011): 295-296; Gil Novales (1975): 1053-1055.

${ }^{34}$ Gil Novales (1975): 1055. 
¿Por qué cuando de todos los países de la culta Europa se presentan hombres amantes de la libertad de los pueblos a combatir en las filas de los griegos nosotros no hemos enviado nuestros diputados a decirles que los hijos del Cid y de Padilla quieren unir sus esfuerzos a los suyos?

El señor Gorostiza llevó más adelante sus observaciones acerca de este asunto: demostró la necesidad de que los pueblos se unieran para defenderse recíprocamente, imitando a los monarcas que, con el objeto de dominar millares de hombres, habían sabido confundir sus intereses y sacrificar una buena parte de sus deseos y ambición para dominar más fácilmente.

Cuando los pueblos libres se hallen unidos, dijo para concluir, ya puede la tierra abortar déspotas, ya pueden estos fabricar cárceles e inventar suplicios; libres seremos, libres moriremos y libres serán nuestros hijos» ${ }^{35}$.

El discurso del periodista y dramaturgo Manuel de Gorostiza ${ }^{36}$ es el primer caso que hemos encontrado documentado sobre la defensa de la causa griega en España de viva voz, apelando directamente al «Ministerio de Estado» para que tome cartas en el asunto, y ante un auditorio tan numeroso que a veces la gente tenía que escuchar desde la puerta del convento de Santo Tomás, con capacidad para unas cuatro mil personas. En esa misma acta se especifica que «Eran cerca de las diez y media que [...] se separó la sociedad, señalando para el jueves inmediato la cuarta sesión pública» ${ }^{37}$.

${ }^{35}$ El Indicador, no 185, 05/11/1822, p. 878, señalado por Gil Novales (1975): 699.

${ }^{36}$ Sobre el mejicano Manuel de Gorostiza y Cepeda $v d$. Gil Novales (1975): 855-845. Hijo de españoles, llegó a ser embajador de Méjico en Londres, pues con el fin del Trienio Liberal sintió que terminaba su ciudadanía española y ofreció sus servicios a su país de origen. Muestra de su radicalismo es una frase suya citada por Gil Novales: «a los liberales españoles se les llama revolucionarios, cuando su verdadero crimen en política es no haber hecho una revolución».

${ }^{37}$ Gil Novales (1975): 681-682. Según El Indicador, no $185,05 / 11 / 1822$, p. 877, la noche en que habló Gorostiza, «Ni el tiempo, ni la oscuridad de la noche, ni el estado del piso, han sido motivos suficientes para retraer al pueblo madrileño, y lo que es más, al bello sexo, de concurrir a Santo Tomás. Desde muy temprano estaban ocupados los asientos de la sala, y obstruidos hasta los claustros que conducían a ella». 


\section{Las gestiones de Luriotis en busca de ayuda para Grecia.}

¿Significa esto que había sesiones "no" públicas? El texto que presentamos como Documento 4, es el borrador de un discurso que Luriotis preparó para unos «Messieurs», que están en un «institut» en el que se ocupan de «les libertés de l'Espagne», y a los que elogia como «hommes libres et amants de la liberté» ${ }^{38}$. Los círculos políticos del Madrid del momento, los contactos que Luriotis debió establecer, los intereses defendidos, todo indica que, si este discurso se llegó a pronunciar, debió serlo en la Landaburiana, y debió ser además en sesión secreta o privada, porque si hubiera sido leído en sesión pública, habría sido recogido en las actas que publicaba El Indicador.

En este discurso, Luriotis se presenta como llegado de Grecia a Madrid en un viaje largo y costoso portando cartas del presidente Mavrocordatos, del ministro de Exteriores Negri y del obispo Ignacio de Pisa, para Díaz de Morales, el Conde de Toreno y Bowring, con el fin de procurar relaciones de amistad y cualquier clase de ayuda proveniente del Gobierno y de los liberales españoles. Dada su delicada situación, antes que dirigirse al Gobierno español, el Gobierno griego ha preferido hacerlo a «ciudadanos respetables», bien que ya se hubieran puesto en contacto con Grecia, como Díaz de Morales y Bowring, o bien cuyo nombre hubiera llegado hasta allí, como el Conde de Toreno, pues ellos sabrían cómo redirigir estas demandas para que fueran entendidas y apoyadas por el Gobierno y por el conjunto de liberales.

Con Díaz de Morales y Bowring ausentes de Madrid, sólo le quedaba Francisco Queipo de Llano, el Conde de Toreno. No obstante, al igual que Díaz de Morales, había cesado en su escaño en febrero de 1822, cuando sufrió un intento de agresión o asesinato a la salida del Congreso por parte de algunos exaltados que no perdonaron su

${ }^{38}$ Vd. Doc. 4 en LAtorre (2012): 233-236 ¿Serían estos «messieurs» los integrantes del Comité Filohelénico español que menciona el Conde de Palma, reunidos en el seno de la Landaburiana? 
moderantismo hipócrita. A partir de este suceso, marchó a París, donde permaneció ya hasta 1833, de manera que Luriotis tampoco pudo entrevistarse con él ${ }^{39}$.

En compensación, Luriotis ha tenido la fortuna de dar con el «brave libéral» «Casa Major / Casa Mayor», quien le ha conducido ante el presente auditorio. Esto sugiere que el Conde de Palma, que en septiembre le había escrito una carta recomendándole a Bowring, no debería estar ya en Madrid cuando se fundó la Landaburiana, pues habría sido él quien le dirigiera allí, y no el enigmático Casa Mayor.

Luriotis expone que ha entregado una Memoria al ministro de Asuntos Exteriores San Miguel cuyo contenido resume a continuación: necesidad que tienen todos los pueblos libres de unirse frente a la amenazante alianza del despotismo, - uno de los principales puntos en el discurso de Gorostiza en la sesión del 3 de octubre-; ventajas que para España, y para Europa entera, traería la constitución de una Grecia libre; y de cómo sin ayuda Grecia no podrá conseguirlo, pues aunque la recibe de particulares, las necesidades que exige duelo tan desigual sólo pueden ser suplidas desde una esfera gubernamental. La conclusión que emanaba de forma natural de la argumentación de Luriotis es que había que ayudar a Grecia para garantizar la libertad en el mundo.

\footnotetext{
${ }^{39}$ Desconocemos cómo pudo llegar a Grecia el nombre de Toreno para que Luriotis lo buscara, aunque es probable que fuera gracias a la fama alcanzada por el libro de Jeremy Bentham Letters to Count Toreno on the proposed Penal Code delivered in by the Legislation Committee of the Spanish Cortes, April 25 ${ }^{\text {th }}, 1821$, written at the Count's request, London 1822. Bentham transcribe la carta, fechada el 6 de agosto de 1821, en la que Toreno le dice que, por mediación de su común amigo John Bowring, le envía el proyecto de ley sobre el Código Penal español para que dé su autorizada opinión; $c f$. pp. iii-iv. Si este libro llegó a Grecia es lógico que pensaran que, puesto que Bowring se había manifestado a favor de Grecia ofreciéndole ayuda, su amigo el Conde de Toreno sería de la misma opinión. No parece probable que fuera el propio Bowring quien mencionara el nombre de Toreno al gobierno griego en alguna carta de la que no tenemos noticia, ya que la comunicación entre Bowring y Grecia comienza a hacerse regular a partir de su contacto con Luriotis en Londres a principios de 1823 y de la fundación del Comité Griego de Londres el 3 de marzo de ese mismo año.
} 
Así pues, mientras espera las decisiones que el ministro español ha de tomar ante las propuestas presentadas en esta Memoria, suplica a su auditorio, «le plus ferme appui des libertés de l'Espagne», que intercedan ante él con el fin de inclinarlo a su favor, y que recuerden que él no solicita una donación, sino un préstamo garantizado, pues los 3/5 de las tierras con las que cuenta el Gobierno griego son confiscadas o confiscables a los turcos.

No pretendemos aquí analizar el texto, que habla por sí solo, sino seguirle los pasos a Luriotis. ¿Quién sería ese «Casa Mayor» que lo condujo hasta la Landaburiana? Gil Novales recoge dos personas bajo este apellido:

1) Faustino Casamayor y Ceballos (Zaragoza 1760-1834), periodista, cuya presencia en Madrid no está atestiguada; y

2) Pablo Casamayor, que aparece relacionado con la sociedad patriótica Amantes del Orden Constitucional el día de su fundación, 7 de junio de $1820^{40}$. Carecemos de más datos sobre Pablo Casamayor, pero sabemos que la Sociedad a la que perteneció, «de un liberalismo dieciochesco y nada democrático», se reunía en la calle Jardines, donde tuvo lugar un curioso incidente: el 9 de agosto de 1820, el napolitano Constantino Viceré invitaba a sus compatriotas italianos a jurar la Constitución Española en la calle Jardines, 52, principal, en la casa de don Ramón de Conti. La Sociedad, tan moderada que terminó derivando en un club de baile, se apresuró a desmentir que esa propuesta tuviera nada que ver con ninguna de sus actividades - «pues no le franquearía la entrada a extranjeros [...] porque respeta sobremanera los derechos de las naciones y gobiernos extranjeros»-, y que el señor Conti vivía en dos habitaciones que la Sociedad le había cedido. Efectivamente, mediante una carta publicada en El Conservador el 20 de agosto de 1820, Viceré confirma que la jura se llevó a cabo en las habitaciones de Conti y no en los locales de la Sociedad ${ }^{41}$. No podemos olvidar que Viceré

${ }^{40}$ Gil Novales (1975): 794.

${ }^{41}$ Gil Novales (1975): 794. 
era el agente en Madrid de Giuseppe Rossaroll, el capitán que llevó a Grecia la expedición de los “300”. El capitán Ramón de Conti aparece en varias sociedades patrióticas -Lorencini, Amigos del Orden Constitucional, La Fontana, La Cruz de Malta-, y fue detenido por haber pronunciado discursos demasiado exaltados en los que avisaba de la mala fe de algunos políticos que ponían en peligro a la patria. Lo más sorprendente es que, después del triunfo del absolutismo, Conti aparece como confidente de la policía al servicio del Rey. Gil Novales se pregunta si siempre lo fue bajo el disfraz de liberal exaltado o si, a partir de 1824, se tornó servil por venganza hacia los liberales moderados que le habían perseguido, pues no hubiera sido éste el único caso $^{42}$. Nada confirma que Pablo Casamayor tuviera más que ver con las actividades que se llevaban a cabo en los locales que la Sociedad cedió a Conti que en la Sociedad misma, lo que le situaría del lado de los exaltados espías o no-, pero es la única pista por proximidad que podemos seguir por ahora sobre el «valiente liberal Casa Mayor».

Otros posibles valedores de Luriotis son Félix Casamayor, oficial retirado de Caballería, y Juan Casamayor, de quienes por el momento sólo sabemos que fueron comuneros reconocidos desde el 12 de octubre de $1821^{43}$.

Un dato importante es que Luriotis dice que ya ha entregado la Memoria al ministro San Miguel y que está a la espera de respuesta, lo que nos da un término post quem, pues esa Memoria, que transcribimos como Documento $5^{44}$, está fechada el 21 de noviembre de 1822 .

Luriotis abre su escrito a Evaristo San Miguel citando la Declaración de los Derechos del Hombre con un alegato sublime contra la Tiranía en favor de la unión de los pueblos bajo el único verdadero soberano de la Tierra, el Género Humano, y bajo su única

\footnotetext{
${ }^{42}$ Gil Novales (1975): 801-802.

${ }^{43}$ Ruiz (2007): 204.

${ }^{44}$ Vd. Doc. 5 en LATORre (2012): 237-241.
} 
legisladora, la Naturaleza. Si existe una Nación merecedora de que le sean aplicados esos derechos, ésa es, sin duda, Grecia, tanto por lo que ha aportado a la civilización como por los beneficios que del triunfo de la libertad de Grecia se derivarían para toda Europa.

Sin entrar en matices, queremos subrayar las dotes diplomáticas de Luriotis para adaptar sus argumentos a cada uno de sus interlocutores. Así, viviendo en Madrid de primera mano las presiones que estaban llegando desde Verona y el revuelo ocasionado por las ya mencionadas protestas patrióticas de San Miguel, en su escrito al presidente subraya la ayuda a Grecia como la oportunidad de salvación de la España libre, incidiendo con más énfasis aún del que lo hace ante ese auditorio indeterminado en la alianza liberticida de los déspotas y en la unión de los pueblos contra ellos. Si Grecia triunfa, la Libertad -la Peste, como la llaman los legítimos- recorrerá Europa, librará a Alemania del despotismo, devolverá a Francia su antiguo puesto de honor entre las naciones libres, y la Península, por fin, podrá vivir tranquila.

Por otra parte, Luriotis también puntualiza que la ayuda solicitada no se trata de una donación, pero mientras que ante el auditorio especifica que la garantía de ese préstamo son los 3/5 de tierras confiscadas a los turcos, en el escrito a San Miguel se muestra más "políticamente correcto" y dice que el Gobierno libre de Grecia cumplirá con sus responsabilidades, sin especificar con qué garantías. Es más, hablando a San Miguel de esos 3/5 de tierras, Luriotis matiza su origen: no son tierras confiscadas a los turcos, sino tierras recuperadas de las confiscaciones que habían hecho los turcos cortando las cabezas de los griegos adinerados. Al fin y al cabo, está tratando con una autoridad legítima, y parece no querer dar la impresión de que son los griegos quienes atentan contra la aún legítima autoridad del Sultán, sino al contrario: los que no han sido respetados por su poder despótico han sido ellos.

Por último, y dado que trata con el principal mandatario español, no quiere pasar por menesteroso. Para intentar hablar de igual a igual, subraya que el «secours moral» es aún más importante que el material, 
invitando a San Miguel a que designe un delegado que acuda a Grecia para tratar todos estos asuntos «d'une grande utilité pour l'Espagne», y añadiendo que el mayor de los secretos encubrirá las decisiones que España tome con el fin de evitar que espías de las Potencias frustren la iniciativa. Luriotis, prudentemente, había omitido este punto en concreto en el discurso pronunciado ante su auditorio, en el que bien podría haberse colado alguno de esos espías. El mero hecho de que esta asamblea de notables se celebrara en privado ya demuestra que el enviado griego tenía perfecta conciencia de que estaba llevando a cabo gestiones de muy alto nivel que exigían enorme discreción y tacto en la España de aquellos días.

En efecto, tan delicada era la situación que, después de haber cantado a la libertad en todos sus aspectos posibles, Luriotis actúa con extrema cautela en la despedida de su carta adulando sin rubor a San Miguel, pues se felicita de la ausencia de las personas a quienes iban dirigidas las cartas originales que el príncipe Mavrocordatos, el ministro de Asuntos Exteriores Negri e Ignacio de Pisa le habían confiado porque eso le había permitido conocer a un Ministro de Asuntos Exteriores «tan liberal» como Su Excelencia. Esto es, así como ante su enigmático auditorio no tuvo problemas en mencionar al Conde de Toreno, Bowring o Díaz de Morales, ante San Miguel silencia sus nombres. Alguien debió avisarle de que Díaz de Morales era otro más de los que no estaban dispuestos a dejar impune el pasteleo de San Miguel, pues si el golpe absolutista del Siete de julio había fracasado había sido gracias a que, con un recibo firmado por el propio Díaz de Morales, la Milicia ciudadana pudo tomar las armas con las que se impuso a la Guardia Real ${ }^{45}$.

\section{Resultados de la misión.}

Luriotis se enfrentó a la paradoja diplomática de que los únicos que habían empatizado con su causa y se habían prestado a escucharle, aquellos a los que pedía que intercedieran por él ante el presidente

\footnotetext{
${ }^{45}$ Gil Novales, Diccionario Biográfico del Trienio Liberal, s. v. Díaz Morales.
} 
San Miguel eran precisamente sus críticos más feroces por haberse dado cuenta de que había cerrado en falso la causa del Siete de Julio favoreciendo de manera indirecta a la reacción absolutista y poniendo así en peligro el sistema constitucional. Por su parte, San Miguel no habría querido tener ni la más mínima relación con nada que viniera de ellos, ni siquiera con un embajador extranjero que aterrizó en Madrid con una misión muy concreta y que se vio, sin pretenderlo, en el ojo del huracán. Los principales oradores de la Landaburiana, en su denuncia constante de los pasteleos presidenciales y de sus fallos de gobierno, llegaron a emplear a Luriotis como arma arrojadiza contra San Miguel, pues el trato que le dispensó es mencionado como la última de una larga retahíla de torpezas:

«El ciudadano Megía (sic) ocupa la tribuna y dice [...] "otra de las cosas que han parecido chocantes en el tiempo del ministerio del señor San Miguel ha sido el modo en que se ha tratado a un griego que se presentó en Madrid poco tiempo hace con credenciales del gobierno establecido en Corinto y en solicitud, al parecer, de ausilios (sic) para aquellos valientes que con tanta decisión defienden su libertad". El orador hizo aquí varias reflexiones para convencer que es de sumo interés el ausiliarse (sic) mutuamente todos los hombres libres para restablecer el imperio de la ley, así como los déspotas se reúnen para destruirla; y continuó diciendo que el señor S. Miguel no se había dignado a oír detenidamente al griego que, aburrido, se tuvo que marchar a Portugal, según que así se había dicho del público en varias tertulias, criticándose una carta que el mismo señor S. Miguel le había dado para un individuo de la embajada de España en aquel reyno, cuya carta concluía en estos términos "y con esto ceso y no derrogar (sic) a Dios guarde su vida muchos años", conclusión, dijo el orador que era de moda en el siglo doce, y que ahora hacía poco favor a la literatura del señor S. Miguel» ${ }^{46}$.

${ }^{46}$ El Indicador, no 239, 29/12/1822, Sociedad Patriótica Landaburiana, 26 de diciembre de 1822. 
Este parlamento de Mejía del 29 de diciembre de 1822 es tan similar al artículo que se publicó en el primer número de El Zurriago de enero de 1823 que ya no puede caber ninguna duda sobre la autoría de este texto, en el que se decía:

«como no encontrase en Madrid al exdiputado Díaz Morales, ni a otros patriotas para quienes venía recomendado, se presentó al ministro San Miguel. [...]. Hemos visto una memoria que el susodicho griego entregó a nuestro ministro [que] nos pareció contener ideas muy luminosas, ideas que hubieran aprovechado mucho a otro ministro o ministros más entendidos y suspicaces; pero en vez de tomarla en consideración su excelencia, la devolvieron sin haberse dignado a contestar siquiera $»^{47}$.

Dos conclusiones podemos extraer de este parlamento de Mejía. En primer lugar, que Mejía se había convertido en uno de los confidentes de Luriotis, pues dice haber visto toda su documentación. De hecho, Luriotis conservó un ejemplar de El Zurriago, que quizá le entregó el propio Mejía y que atestigua su presencia en la Landaburiana, pues es el número correspondiente a la segunda semana de noviembre, esto es, tan sólo una semana después de que Gorostiza apelara al Ministerio de Estado en su alegato a favor de la causa griega ${ }^{48}$.

En segundo lugar, Mejía protegió el prestigio de la misión de Luriotis citando al "patriota» Díaz de Morales como su persona de contacto y omitiendo a la vez al Conde de Toreno, pues habría supuesto un verdadero desdoro para el agente griego relacionarlo con él ante un auditorio como el de la Landaburiana, y además, en justicia, sólo lo conocía de oídas. Esto puede ser una buena muestra de la tensión política que reinaba en el Madrid de aquellos días, pues ante San Miguel había que evitar el nombre de Díaz de Morales, y ante

${ }^{47}$ El Zurriago, no 83-84, pp. 11-12. Pasaje completo en LAtorre (2011): 287.

${ }^{48}$ El Zurriago no 75-76 (INE K $\Delta^{\prime}$ 19). Si bien tendía a ser semanal, El Zurriago no tenía fecha fija de salida, por lo que su cronología debe ser relativizada. La noticia más reciente que recoge el no 75-76 data del 6 de noviembre de 1822, y el no 77-78 trae la fecha del 15 de noviembre. 
la Landaburiana había que omitir al Conde de Toreno, considerado por los exaltados como uno de los personajes más deletéreos que pudo llegar a tener la España constitucional.

En resumidas cuentas, las largas horas pasadas por Luriotis en las dependencias del Ministerio habían sido en vano. Da la impresión de que a fuerza de tesón San Miguel se vio obligado a recibirlo, pero lo hizo de manera expeditiva y sin atender a sus razones, indicándole la salida de España con la carta en la que le recomendaba a la embajada de Lisboa ${ }^{49}$. No podemos afirmar cuál sería la opinión personal de San Miguel sobre la causa griega ${ }^{50}$, pero creemos que lo único que el presidente pretendía era no aumentar con un problema ajeno el buen montón de problemas propios que tenía ya. La persistencia de Andreas Luriotis debía de colocarle en una posición comprometida: probablemente, ni se atrevía a irritar aún más los ánimos de Verona prestándole demasiada atención a un enviado de los revolucionarios griegos - otro de los grandes demonios de las Potencias- ${ }^{51}$, ni aunque hubiera querido apoyar la causa griega, podía permitirse

${ }^{49}$ Recordemos que el Conde de Palma decía: «The Minister for Foreign Affairs, San Miguel, had treated him with the same courtesy as he had treated the Holy Alliance», $c f$. nota 7. Forsyth, el embajador norteamericano en Madrid, hablaba de «coldness», $c f$. Doc. 7.1 en LATORRE (2012): 242-243.

${ }^{50}$ San Miguel fue el editor de El Espectador, que en las noticias de actualidad que transmite durante 1821 y 1822 siempre se presenta favorable a los griegos. Por citar un buen ejemplo: «La Puerta, además, tiene siempre el mismo lenguaje o, por mejor decir, la misma conducta, pues no ha cesado de decir que antes que transigir con la Rusia quiere someter a los griegos. Es cierto que si se aguarda esta sumisión se aguardará probablemente aún mucho tiempo, a no ser que supongamos que la nación griega está en vísperas de ser aniquilada, pues en lenguaje turco someter a los griegos es degollarlos en masa», $c f$. $E l$ Espectador, 05/07/1822, p. 1. No obstante, no hemos conseguido localizar ninguna noticia relativa a la visita de Luriotis a Madrid. El Espectador y El Zurriago terminaron el Trienio Liberal enfrentados a muerte.

${ }^{51}$ El Zurriago, n 74, p. 1, abría con las noticias de que en el Congreso de Verona había cinco puntos a tratar: Nápoles, Grecia, España, sociedades secretas y restablecimiento de la censura. Es seguro que los reunidos en Verona estarían puntualmente informados gracias a sus espías de todos los movimientos de Luriotis en Madrid, y que estarían pendientes del más mínimo cambio en la situación. Por otra parte, los congresistas se negaron en redondo a recibir siquiera a la embajada que el Gobierno de Grecia envió a Verona, $c f$. infra. 
el lujo de prescindir de unos recursos, hombres y armas que iba a necesitar en breve. El futuro estaba a punto de concretarse en cruda realidad al otro lado de los Pirineos, y ya no había tiempo material para que el sueño griego de la libertad recorriendo Europa fraguara hasta convertirse en el garante de la España libre y constitucional.

\section{Luriotis en la Embajada de Estados Unidos en Madrid.}

Desconocemos si los confidentes españoles de Luriotis llegaron a saber todas las gestiones que llevó a cabo en Madrid, porque el propio secretismo con que envolvió su misión casi la sepulta en el olvido, pero, como buen diplomático, no se marchó sin agotar todas las posibilidades.

Resistiéndose a abandonar Madrid con tanta frustración como expectativas había traído a ella, cuando Luriotis vio que nada podía esperar ya del Gobierno español, optó por dirigirse a la Embajada de Estados Unidos, sita en aquellos entonces en la calle Fuencarral y regentada por Mr. John Forsyth ${ }^{52}$. El Gobierno Provisional griego consideraba vital establecer relaciones con los Estados Unidos por el poder que ya estaban desplegando en el panorama internacional y, en concreto, por su decisiva intervención a favor de la independencia de las repúblicas latinoamericanas, independencia que Grecia también creía merecer ${ }^{53}$. Por otra parte, uno de los recursos empleados por Luriotis para estructurar su discurso era aludir a los Estados Unidos de América: si las Potencias europeas les habían ayudado en su Guerra de Independencia contra un poder que no era ni mucho menos tan despótico como el que sufría Grecia, ¿por qué a Grecia se le negaba esa misma ayuda cuando sólo quería fundar una nación basada en esos mismos principios?

\footnotetext{
${ }^{52}$ Kalendario Manual y Guía de Forasteros en Madrid, 1822, p. 46.

${ }^{53}$ En junio de 1823, cuando Luriotis se encuentra en Tripolitza preparando su segundo viaje a Londres para iniciar las negociaciones del empréstito, recibe directrices meridianas de Mavrocordatos en persona: las relaciones con Estados Unidos son decisivas, y tiene carta blanca para negociar cualquier cosa que resulte ventajosa para Grecia a cualquier precio con las embajadas de Estados Unidos en Londres y París, con las que debe entablar contacto con la mayor discreción posible. Cf. Apología, p. 15.
} 
Forsyth tampoco accedió a sus propuestas, pero al menos le trató con cortesía. A través de un billete escrito un «domingo» — quizá el 1 de diciembre de 1822 - a las cinco de la tarde, le cita a las ocho de la noche para devolverle los documentos que le había dejado «y presentarle a una de sus compatriotas». La nota es ambigua y no podemos saber si la compatriota lo era de Luriotis o del embajador norteamericano ${ }^{54}$. El 13 de diciembre Forsyth escribía al secretario de Estado John Quincy Adams relatándole lo acontecido ${ }^{55}$ y remitiéndole la traducción al inglés de los documentos que Luriotis le había entregado. Gracias a este despacho rutinario sabemos que en esa fecha Luriotis ya había marchado a Lisboa y, lo más importante, se ha conservado en su traducción inglesa el informe, que creíamos perdido, sobre el estado de Grecia en abril de 1822 que Negri prometía a Díaz de Morales para convencerle de que, con la buena marcha que llevaba la Revolución, la ayuda a Grecia era una inversión de futuro. Este informe lleva el $n^{\circ}$ de Protocolo 66 del Ministerio de Asuntos Exteriores griego, lo que lo hace correlativo de la propia carta de Negri, que lleva el no $65^{56}$.

\section{Entre Cádiz y Lisboa: la carta de Díaz de Morales a Louriotis.}

Las andanzas de Luriotis en Lisboa esperan aún a ser relatadas, pero hay varios detalles que lo muestran como un hombre inasequible al desaliento.

Luriotis no se resigna a seguir en la Península Ibérica sin contactar con Díaz de Morales, y el 7 de enero, cuando debería llevar unas dos semanas en Lisboa, le escribe a Cádiz contándole lo sucedido y formulándole una pregunta concreta que desconocemos. El 21 de enero Díaz de Morales le contesta con una carta breve pero intensa: se congratula de poder contribuir a la causa griega, pero aún no puede "dar una respuesta terminante», desafortunadamente no sabemos a qué. No obstante, le promete en breve una segunda carta

\footnotetext{
${ }^{54}$ Vd. Doc. 6 en Latorre (2012): 242. Cf. LAtorre (2011): 288.

${ }^{55} \mathrm{Vd}$. Doc. 7.1 en LATORRe (2012): 242-243.

${ }^{56} \mathrm{Vd}$. Doc. 7.2 en LATORRE (2012): 243-246.
} 
con reflexiones que podrán serle muy útiles para obtener resultados positivos en favor de Grecia. Lamenta también no haber podido estar con Luriotis en Madrid, pues los resultados de sus gestiones habrían sido muy distintos, pero otros asuntos más urgentes le retenían en Cádiz. Finalmente, se despide pidiéndole que siga contando con él y ofreciéndose «de la manera franca e ilimitada que caracteriza a los amigos de la libertad del género humano» ${ }^{57}$.

En aquellos días de enero de 1823 Díaz de Morales estaba en Cádiz fundando una Sociedad patriótica en honor de Santiago Jonama, periodista al que el presidente Evaristo San Miguel había expulsado de Madrid con el fin de abortar la publicación de un periódico que sacaría los trapos sucios del enjuague que había hecho de la causa del Siete de $\mathrm{Julio}^{58}$. Díaz de Morales parece sincero en su disposición, pero él, como el resto de liberales españoles, tenía en su propia casa demasiadas cosas que arreglar y que no podía abandonar por intereses ajenos, por muy loables que estos fueran. Quizá el propio Díaz de Morales no fuera consciente, pero ya había dicho eso mismo un año antes en la carta que envió a Grecia junto con Bowring y Palma desde el Comité Filohelénico ofreciendo los servicios de los 300 italianos pero no de los españoles, que tenían «que afianzar su propia libertad». Si no se hubieran producido los sucesos del Siete de Julio y el sistema constitucional en España se hubiera ido consolidando, quién sabe si la historia de la Revolución griega no hubiera sido algo distinta.

En cualquier caso, si Díaz de Morales llegó a escribir la segunda carta con las prometidas reflexiones, Luriotis no la recibió, quizá por no estar ya en Lisboa. Un término post quem que nos permite datar su periplo viene dado por un ejemplar del periódico Astro da Lusitania del 30 de enero de 1823, el cual conservó, quizá, para justificarse ante su Gobierno, que a duras penas habría creído el relato de los desaires recibidos y hubiera podido achacar tanto fracaso a falta de aplicación por su parte:

\footnotetext{
${ }^{57} \mathrm{Vd}$. Doc. 8 en LATORRe (2012): 250-251.

${ }^{58}$ Gil Novales (1975): 416.
} 
"Que dirá o governo de Corintho, quando souber que o seu actual Encarregado dos negocios em Lisboa nâo só nâo tem obtido algum soccorro, ou promessa delle [...], mas que até foi tractado com indecencia por alguns homens a quem se dirigio? Quando este disser, v. g., que hum dos principaes agentes do governo teve, e gouardou em seu poder pelo espaço de 10 dias os titulos do dito Encarregado, satisfazendo-o depois com vâos discursos; que outro individuo membro do Congresso nacional, lhe pagou na mesma moeda; e que tanto a casa de hum, como de outro tem ido immensas vezes, mas sempre inutilmente, tendo-se-lhe antes designado a hora para comparecer? Que dirá, quando souber que o seu Encarregado de negocios tem passado 30 horas na antecamera destes dois novos fidalgos portuguezes? ${ }^{59}$

El trato recibido en Lisboa debió suponer para Luriotis un simple déjà vu de lo que le había acontecido en Madrid. Siguiendo los consejos que ya en septiembre le dio el Conde de Palma, Andreas Luriotis emprendió viaje a Londres en busca de nuevas oportunidades no sin antes, como era habitual en él, haber llevado a cabo los contactos que considerara más provechosos.

El 22 de febrero se presenta ante Richard Rush, el embajador de Estados Unidos en Londres, con una carta de recomendación del general Dearborn en Lisboa. Al informar de este encuentro al Secretario de Estado Quincy Adams, Rush dice que Luriotis ha llegado «recientemente» ${ }^{60}$. El embajador norteamericano transmitió a Luriotis la simpatía por su causa, pero alegó que la política de

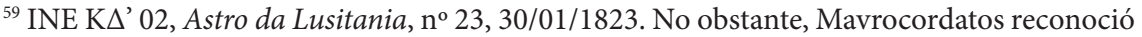
expresamente su trabajo cuando le encomendó las negociaciones del préstamo a través del Comité Griego de Londres en junio de 1823: «Le zèle que vous avez manifesté dans votre dernière mission en Europe, votre conduite aussi sage que conforme à vos devoirs, et les relations utiles que vous avez contractées, et dont vous avez rendu compte à votre arrivée ici, persuadent le gouvernement que vous ferez utiliser ces mêmes relations dans votre mission actuelle», cf. Apología, p. 17.

${ }^{60}$ Message, pp. 13-14.
} 
no injerencia de los Estados Unidos en asuntos de otras naciones le impedía ofrecerle ninguna ayuda efectiva hasta que Grecia se consolidara como Estado, y Luriotis se tuvo que conformar.

Muy distinta es la historia a partir de su encuentro con John Bowring, gracias a la carta de recomendación que le escribiera en Madrid el Conde de Palma. El 3 de marzo de 1823 se funda el Comité Griego de Londres, del que Bowring es secretario y Jeremy Bentham uno de sus principales valedores, y el 4 de marzo Andreas Luriotis y el irlandés Edward Blaquières ${ }^{61}$ parten rumbo a Corinto para consultar con Mavrocordatos las condiciones del préstamo propuesto por el Comité para apoyar la lucha. De paso por Génova, el 5 de abril, solicitan una entrevista a Lord Byron, quien se muestra encantado de recibirles. Pero eso ya es otra historia, la historia conocida.

\section{Conclusiones.}

La secuencia de los acontecimientos relacionados con la misión de Luriotis en Madrid es la siguiente:

- Septiembre de 1822: Llegada a Madrid y entrevista con el Conde de Palma.

- Octubre: Sin noticias.

- 3 de noviembre: Gorostiza pronuncia un discurso en la Landaburiana en pro de la causa griega en el que apela al Ministerio de Estado y que articula sobre las reivindicaciones de Luriotis: ayuda gubernamental a Grecia y unión de los pueblos libres frente a la alianza de los déspotas.

- 6-15 de noviembre: El ejemplar de El Zurriago n 75-76 conservado por Luriotis demuestra que mantuvo contactos con miembros de la Landaburiana, al menos con Félix Mejía y Benigno Morales.

- 21 de noviembre: Luriotis se entrevista con San Miguel y le entrega los documentos del Gobierno griego.

${ }^{61}$ ST. ClaIr (2008): 142, afirma que fue Edward Blaquières quien acompañó a Luriotis desde Madrid hasta Londres; BREwER (2001): 196-197, por el contrario, cree que Blaquières ya estaba en Londres cuando Luriotis llegó allí. 
- post 21 de noviembre: Presentado por Casa Mayor, Luriotis habla en sesión privada ante los notables de la Landaburiana para que le apoyen en su gestión.

- ca. 1 de diciembre: San Miguel ya ha devuelto a Luriotis la Memoria de Negri sin contestar junto con una carta de recomendación para la embajada española en Lisboa. Luriotis agota posibilidades y se dirige al embajador de Estados Unidos en Madrid, John Forsyth.

- inter 1-13 de diciembre: Luriotis se ha vuelto a entrevistar con Forsyth y ya ha emprendido viaje a Lisboa.

- 13 de diciembre: Forsyth escribe a John Quincy Adams contándole lo sucedido y adjuntándole traducción al inglés de la documentación de Luriotis.

- 26 de diciembre: Félix Mejía critica en la sesión pública de la Landaburiana el trato vejatorio que el enviado griego ha sufrido por parte de San Miguel.

- ca. 1 de enero de 1823: Félix Mejía publica en El Zurriago n 8384 lo acontecido con Luriotis, divulgando así la noticia, que se comentó mucho en las tertulias madrileñas, a nivel nacional.

- 7 de enero: Desde Lisboa, Luriotis escribe a Díaz de Morales en Cádiz.

- 21 de enero: Respuesta de Díaz de Morales apoyando su causa y prometiendo una segunda carta no conservada.

- 30 de enero: El ejemplar de Astro da Lusitania denunciando el trato recibido por Luriotis es la última prueba de su presencia en Lisboa.

Así pues, el agente griego estuvo en Madrid desde un día indeterminado de septiembre hasta los primeros días de diciembre de 1822, entre dos y tres meses, los más frenéticos políticamente hablando de todo el Trienio Liberal. Resulta difícil de creer que un hombre de la diligencia de Luriotis permaneciera inactivo durante los días de septiembre y todo el mes de octubre que pasara en Madrid. Si el Conde de Palma le informó de que ya ninguno de sus contactos se encontraba en Madrid, Luriotis debió iniciar gestiones para entrevistarse con el presidente Evaristo Fernández San Miguel 
o con algún otro miembro del Gobierno. Por otra parte, no puede ser casual que, después de que Luriotis llevara mes y medio en Madrid haciendo su trabajo con la dedicación que ya hemos visto, el 3 de noviembre Gorostiza intentara implicar al Ministerio de Estado pronunciando desde la tribuna de la Landaburiana el primer discurso de apoyo a la causa griega documentado en España y basado además en el argumentario de Luriotis. Por otra parte, Gorostiza habla en términos generales y no desvela públicamente la presencia de un enviado griego en Madrid - que con toda seguridad se hallaría incluso presente entre el auditorio-, pero del que el Ministerio de Estado tendría conocimiento sobrado.

Si a esto le sumamos la discreción con que Luriotis llevó a cabo sus gestiones, todo induce a pensar que Gorostiza, Mejía, Benigno Morales y otros notables de la Landaburiana trazaron una suerte de estrategia de comunicación que pudiera contribuir al éxito de la misión del amigo griego, pues da la impresión de que, sabedor de las largas y vanas esperas a las que San Miguel debió someter a Luriotis, Gorostiza pretendió con su discurso poner en primer plano de actualidad la situación de Grecia y sensibilizar a la opinión pública con el fin de que, aunque fuera de manera indirecta, San Miguel se viera presionado para entrevistarse con el griego. Al fin y al cabo, cada una de las sesiones de la Landaburiana era un acontecimiento al que acudía un nutridísimo número de personas y se comentaba en todas las tertulias de la capital.

Bien por esta presión de la opinión pública que hoy nos es muy difícil rastrear, bien por la imagen de un Luriotis perenne mirándole desde la antesala de su despacho, San Miguel accedió a recibirle, probablemente el 21 de noviembre, fecha de la carta que Luriotis le dirige. No tardaría mucho en celebrarse la sesión privada con los notables de la Landaburiana en la que Luriotis les comunica el avance de sus gestiones, de las que seguramente ese grupo selecto de patriotas estarían enterados. Dosificando la información de forma magistral, Luriotis les hace partícipes de algunos detalles del proyecto griego 
que hasta ahora había guardado con discreción, como el modo en que se iba a financiar esa liberación, para convencerlos de que deben interceder a su favor ante el Presidente en tanto él toma una decisión al respecto. Así pues, vuelve a incidir en las enormes ventajas que supondría para España una Grecia libre, musa inspiradora de todos los libertarios oprimidos que harían caer los gobiernos despóticos como las fichas de un dominó. Europa sería libre y la España libre podría afianzarse por fin sin presiones externas.

Andreas Luriotis había vivido in situ la creciente inquietud que generaban las noticias que llegaban de Verona mientras el sistema constitucional se estaba desmoronando, y sabía que el único argumento válido para que España se decidiera a ayudar a Grecia era ofrecerle una quimera - la unión de los pueblos libres frente a la alianza de los déspotas- que conjurara el fantasma de una invasión anunciada y que ofreciera a la agonizante España libre una próspera esperanza de futuro teñida del fulgor siempre irresistible de la Grecia eterna.

Fracasó, y no por falta de mérito, sino porque las circunstancias dictaban que tenía muy pocas probabilidades de triunfar. A principios de diciembre San Miguel ya le había mostrado el camino de Lisboa y había quemado su último cartucho en la embajada norteamericana de la calle Fuencarral. Con su estratégica misión secreta convertida en un fiasco, Luriotis abandona Madrid. Sin temor ya a perjudicarle, Félix Mejía puede romper la confidencialidad que había rodeado los movimientos de Luriotis y denunciar en público el trato dispensado al enviado griego que traía «ideas muy luminosas» por un presidente torpe y traidor que estaba cavando la fosa del país. Es evidente que Mejía hizo un uso político de la misión de Luriotis, y es muy probable que Mejía, Gorostiza y el resto de patriotas que le brindaron su protección supieran que la ayuda a Grecia era un deseo imposible de cumplir, pero Luriotis supo crear para ellos un clima casi de conspiración internacional del que surgía la emoción de estar participando en algo muy grande, aderezado de un ideario con el que se sentían plenamente identificados y en cuya defensa muchos de 
estos hombres que se relacionaron con Luriotis entregaron sus vidas, ya en el paredón, ya en una cárcel insalubre, ya en la tristeza del exilio. Todos ellos habrían suscrito sin dudar la frase final que su compañero de lucha Díaz de Morales escribió en su carta a Luriotis, pues todos se ofrecieron «de la manera franca e ilimitada que caracteriza a los amigos de la libertad del género humano».

Aunque el diplomático Luriotis pudo personalizar el argumentario revolucionario griego cargando las tintas sobre lo que España quería escuchar para intentar conseguir su objetivo, transmite una sensación de gran soltura al presentar a Grecia como un Estado regido por una Ley Orgánica que quiere autogestionarse como nación, de lo que se puede deducir que, tanto sus propias convicciones como las directrices que había traído de Corinto le guiaban en ese sentido. De hecho, Negri le entregó una copia de esa Ley para demostrar allá donde fuera que Grecia renacía civilizada y constitucional en consonancia con los tiempos modernos.

Gracias a la proyección de esta imagen, la causa griega es asumida como propia por el sector exaltado del liberalismo europeo por ser una lucha entre Despotismo y Libertad, precisamente lo que horripilaba a las Potencias de Verona y lo que las dos únicas naciones -España y Portugal- cuyas revoluciones aún persistían habían intentado maquillar con monarquías constitucionales. El tono en que Luriotis escribe sus cartas, desde luego, no deja lugar a dudas: todos sus argumentos son puramente políticos de clara raigambre revolucionaria y burguesa sin concesiones al factor religioso. En un momento dado, incluso previene a su auditorio privado de que si la libertad no triunfa en Grecia y, por tanto, en Europa, España se plegará de nuevo a la doble tiranía que pesaba sobre ella antes de 1820, la eclesiástica y la civil ${ }^{62}$.

Está claro que Luriotis emplea este argumento influido por la propaganda que las Potencias habían hecho correr sobre el

${ }^{62}$ Vd. Doc. 4 en LAtorre (2012): 235. 
anticlericalismo de la España constitucional, creyendo también que esto era lo que los liberales españoles querían oír. No obstante, para Grecia la religión no suponía una tiranía, sino un factor fundamental de su identidad. Tal y como Luriotis le dice a San Miguel, «Les Grecs non, ils ne retourneront pas sous le joug ottoman», y estaban dispuestos a conseguirlo al precio que fuera.

Tanto es así, que mientras Luriotis estaba en España defendiendo la independencia griega desde un punto de vista constitucional y libertario, el Gobierno enviaba a las Potencias reunidas en el Congreso de Verona una embajada con el Conde Metaxás al frente de la que formaban parte, entre otros personajes ilustres, Germanós, metropolita de Patras, y el coronel Philippe Jourdain, con el fin de solicitar un rey cristiano que uniera las Iglesias de Oriente y Occidente bajo la figura del Pontífice de Roma. Sin embargo, esta estrategia tampoco resultó válida. La asamblea de Verona se negó a recibirles dando la orden de que quedasen retenidos en Ancona, y sólo a través del nuncio del papa Pío VII, el cardenal Spina, lograron hacer llegar a Verona una petición de ayuda, que fue repudiada por el canciller Metternich. Dado que ni siquiera le fue permitido llegar a Roma, Germanós ya nada dijo sobre la cuestión de la unión de las Iglesias $^{63}$, y esta propuesta cayó en el olvido ${ }^{64}$.

La misión de Luriotis en España y los argumentos que en ella esgrimió demuestran que Grecia quería, ante todo y sobre todo, su

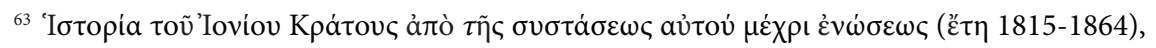

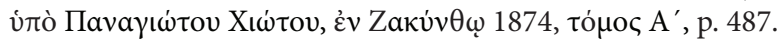

${ }^{64}$ Dalleggio (1949): 33-36. Dado el estrepitoso fracaso, el contenido de esta embajada debió de archivarse con discreción, y con toda seguridad Luriotis lo desconocía. No obstante, salió a la luz cuando el 24 de mayo de 1825, el capitán Nicólaos Kefalás consigue una audiencia con el papa León XII haciéndose pasar por plenipotenciario del Gobierno griego y por propia iniciativa le reitera punto por punto la propuesta que la embajada, entonces sí oficial, había querido llevar a Verona: Grecia solicitaba un rey europeo que reuniera la Iglesia ortodoxa y la católica según el espíritu de los Concilios de Basilea y Florencia 1431-1445. Ioannis Orlandos y Andreas Luriotis, entonces agentes en Londres, escriben urgentemente a su Gobierno para denunciar el fraude y evitar en lo posible el escándalo enviando incluso prensa donde se trataba el tema, aunque en Grecia el asunto era ya conocido. El Gobierno griego desautorizó a Kefalás y el Papa se vio liberado de una decisión muy comprometida. Cf. también FischetTi (1975): 266-267. 
libertad, y como nación en construcción estaba abierta a todas las opciones posibles que le permitieran configurarse como tal. Grecia se habría constituido de un modo u otro en un país cristiano, y en virtud de ese factor pidieron auxilio a unas Potencias que, si bien cristianas, permanecieron inconmovibles en un principio ante este argumento religioso, mientras que otros colectivos sí fueron receptivos al mensaje de libertad que emanaba de la insurrección contra el Déspota por antonomasia. En la primera época de la Revolución no hay todavía exclusivismo en la utilización del argumento Cristianismo vs. Islam, que con el tiempo se convertirá en el principal y casi único estandarte que enarbolarán las Potencias cuando cambien su actitud frente a la Revolución griega en función de los intereses que ha creado la nueva situación en el Mediterráneo oriental. Esta idea de "nueva Cruzada", que terminará contaminando todo lo relacionado con la lucha griega, permitirá remozar el filohelenismo insurreccionista originario para transformarlo en un filohelenismo cristianizado sin ningún poder ya de transgresión que Grecia tendrá que terminar asumiendo sin matices, porque será la única opción que le dejen para lograr ser aceptada por fin en el concierto de las naciones.

${ }^{*}$ Trabajo realizado en el marco del proyecto de investigación FFI201129696-C02-01, adscrito al CCHS-CSIC. Una primera versión de este trabajo fue publicada bajo el título "Los amigos de la libertad: documentos sobre el filohelenismo español (1821-1823)», en Erytheia, Revista de Estudios Bizantinos y Neogriegos, 33 (2012), pp. 195-251, Madrid: Asociación Cultural HispanoHelénica, en la que se incluyó un apéndice (pp. 227-251) con la edición de los ocho documentos originales a partir de los cuales está desarrollado el presente ensayo. Las referencias que hagamos a estos documentos podrán consultarse en el mencionado trabajo, citado en lo sucesivo como Latorre (2012). Deseo agradecer también desde aquí al Prof. Pedro Bádenas de la Peña las facilidades que puso a mi disposición para poder llevar a cabo en Atenas la labor de investigación que ha dado origen a estos artículos, así como el asesoramiento que tanto él como Carlos Morales Martín me prestaron en la transcripción de los documentos manuscritos en francés que fueron editados en el trabajo anterior. 


\section{Referencias bibliográficas}

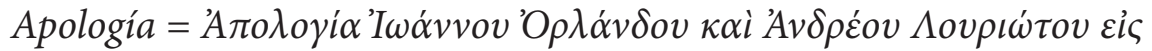

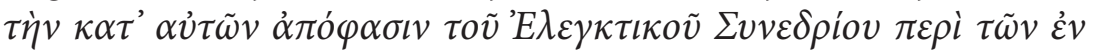

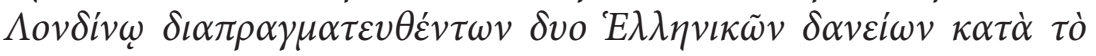

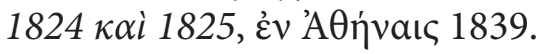

Barth, W.-Kehrig-Korn, M. (1960), Die Philhellenenzeit. Von der Mitte des 18. Jahrhunderts bis zum Ermordung Kapodistrias' am 9. Oktober 1831. München: Verlag.

Brewer, D. (2001), The Greek War of Independence. Woodstock \& New York: The Overlook Press.

Conde de Palma, Greece vindicated; in two letters, by Count Alerino de Palma, to which are added, by the same author, critical remarks on the works recently published on the same subject, by Messrs. Bulwer, Emerson, Pecchio, Humphreys, Stanhope, Parry \& Blaquière, 1826. London: British Library.

Dalleggio, E. (1949), Les Philhellènes et la Guèrre de l'Indépendance. Lettres inédites de J. Orlando et A. Louriotis. Athènes: Institut Français d'Athènes.

Fischetti, G. (1975), «Ancora sulla questione Foscolo e Kefalàs (con lettere inedite)», Giornale storico della letteratura italiana 152.2, pp. 266-275. Torino: Loescher Editore.

Gil Novales, A. (1975), Las sociedades patrióticas (1820-1823). Las libertades de expresión y de reunión en el origen de los partidos polítcos, 2 vols. Madrid: Tecnos.

Jasiotis (2008) = Hassiotis, Y., «El filohelenismo español», Tendiendo puentes en el Mediterráneo. Estudios sobre las relaciones hispano-griegas (ss. XV-XIX), Granada, pp. 117-128. Granada: Centro de Estudios Bizantinos, Neogriegos y Chipriotas.

JADSigueorguíU-Jasioti (2000) = Hatsigueorguiou DE HAssiotis, V., «El filohelenismo español durante el siglo XIX», España y la cultura hispánica en el sureste europeo, Atenas: Embajada de España, pp. 144-155. 
LAtorre Broto, E. (2011), «Los filohelenos españoles: estado de la cuestión y actualización de nómina», Erytheia. Revista de Estudios Bizantinos y Neogriegos 32, pp. 279-319. Madrid: Asociación cultural Hispano-Helénica.

LAtorre Broto, E. (2012), «Los amigos de la libertad. Documentos sobre el filohelenismo español (1821-1823)», Erytheia. Revista de Estudios Bizantinos y Neogriegos 33, pp. 195-251. Madrid: Asociación cultural Hispano-Helénica.

LLORENS, V. (2006), Liberales y románticos. Una emigración española en Inglaterra. Madrid: Castalia.

Message $=18$ th Congress, 1st Session. Message from the President of the United States, transmitting a Report of the Secretary of State upon the subject of the present condition and future prospects of the Greeks. December, 31st 1823, Washington 1824.

Ruiz Jiménez, M. (2007), El liberalismo exaltado. La confederación de comuneros españoles durante el Trienio Liberal. Madrid: Fundamentos.

Simón Díaz, J. (1986), «Bibliografía madrileña en el siglo XIX», en Madrid en la sociedad del siglo XIX, vol. 2. Madrid: Consejería de Cultura de la Comunidad de Madrid.

St. Clair, W. (2008), That Greece might still be free. The Philhellenes in the War of Independence, $2^{\mathrm{a}}$ ed. del original de 1972 corregida y aumentada. Cambridge: OpenBook Publishers.

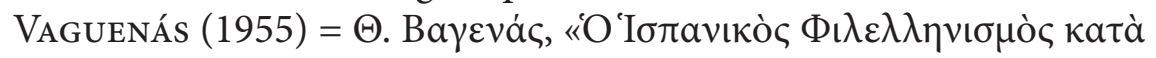

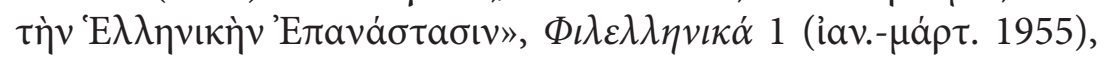

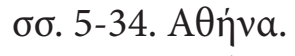

Zavala, I. M. (1971), Masones, comuneros y carbonarios. Madrid: Siglo XXI.

\section{Abreviaturas empleadas}

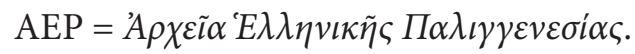

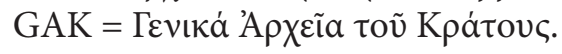

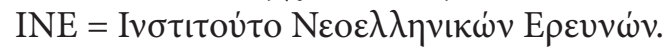

